\title{
Predictors of survival after cardiac or respiratory arrest in critical care units
}

\author{
Demetrios J. Kutsogiannis MD MHS, Sean M. Bagshaw MD MSc, Bryce Laing MD, Peter G. Brindley MD
}

See related commentary by Abella on page 1572 and at www.cmaj.ca/lookup/doi/10.1503/cmaj.110982

\begin{abstract}
Background: Survival outcomes after cardiac or respiratory arrest occurring outside of intensive care units (ICUs) has been well described. We investigated survival outcomes of adults whose arrest occurred in ICUs and determined predictors of decreased survival.

Methods: We reviewed all records of adults who experienced cardiac or respiratory arrest from Jan. 1, 2000, to Apr. 30, 2005, in ICUs at four hospitals serving Edmonton, Alberta. We evaluated patient and clinical characteristics, as well as survival outcomes during a five-year follow-up period. We determined risk factors for immediate (within 24 hours) and later death.

Results: Of the 517 patients included in the study, $59.6 \%$ were able to be resuscitated, $30.4 \%$ survived to discharge from ICU, $26.9 \%$ survived to discharge from hospital, $24.3 \%$ survived to one year, and $15.9 \%$ survived to five years. Pulseless electrical activity or asystole was the most common rhythm $(45.8 \%$ of the arrests). Survival was lowest among pa-

tients with an arrest due to pulseless electrical activity or asystole: only $10.6 \%$ survived to one year, compared with $36.3 \%$ who had other arrest rhythms $(p<0.001)$. Independent predictors of decreased later survival (eight months or more after arrest) were increasing age (adjusted hazard ratio [HR] 1.06, $95 \%$ confidence interval $[\mathrm{Cl}] 1.03-1.09)$ and longer duration of cardiopulmonary resuscitation (CPR) (adjusted HR 1.38, 95\% Cl 1.031.83, per additional logarithm of a minute of (PR).

Interpretation: Our study showed no major improvement in survival following cardiac arrest with pulseless electrical activity or asystole as the presenting rhythm in the ICU despite many advances in critical care over the previous two decades. The independent predictors of death within 24 hours after arrest in an ICU were sex, the presenting rhythm and the duration of CPR. Predictors of later death (eight months or more after arrest) were age and duration of CPR.
\end{abstract}

Competing interests: Sean Bagshaw has received consultancy fees from Spectral Diagnostics Inc. and Baxter Inc., and speaker fees from Gambro Renal Products Inc. and Alere Inc. Peter Brindley received travel support from Pfizer to attend the 31st International Symposium on Intensive Care and Emergency Medicine. No competing interests declared by Demetrios Kutsogiannis and Bryce Laing.

This article has been peer reviewed.

Correspondence to: Dr. Peter G. Brindley, peter.brindley@ albertahealthservices.ca

CMAJ 2011. DOI:10.1503 /cmaj.100034 ardiac arrest remains a major clinical and public health problem. ${ }^{1}$ Studies of cardiac arrest involving patients admitted to non-critical care beds showed that survival has not improved despite 40 years of medical advances..$^{2-4}$ Outside of critical care units, survival was substantially lower for nonwitnessed arrests than for witnessed arrests; for cardiac than for respiratory arrests; for arrests due to asystole or pulseless electrical activity than for those due to ventricular fibrillation or ventricular tachycardia; and for arrests occurring early in the morning than for those at other times of the day. ${ }^{2-4}$ How these data apply to approximately one-third of in-hospital cardiac arrests that occur in intensive care units (ICUs) is less clear.

Arrests in ICUs might be expected to have increased survival because universal cardiac monitoring and a high nurse-to-patient ratio would mean that the arrests would be witnessed regardless of the time of day. On the other hand, survival might be expected to be lower because critical care patients have a high disease burden and experience arrests despite aggressive preemptive life support. Also, patients in a general ICU might be expected to have poorer survival than those in a coronary care or cardiovascular surgical ICU because they typically have primary noncardiac diagnoses; therefore, cardiac arrest in these patients implies cardiovascular collapse in addition to noncardiac illness (i.e., at least two-organ failure). ${ }^{3,4}$

We evaluated survival outcomes during a five-year follow-up period among adult patients who experienced cardiac or respiratory arrest in ICUs at four hospitals. We also identified risk factors associated with decreased survival after 24 hours. 


\section{Methods}

\section{Study setting}

We conducted the study at four hospitals in Edmonton, Alberta: the University of Alberta and Royal Alexandra Hospitals (the largest tertiary care hospitals in the city) and the Grey Nuns' and Misericordia Hospitals (the largest community hospitals). Combined, these four hospitals provide tertiary care for more than 1.5 million adults. Collectively, the hospitals have about 130 adult critical care beds (defined by capacity for continuous monitoring, one-on-one nursing and mechanical ventilation): 40 beds in coronary care units, 70 beds in multidisciplinary general ICUs and, at the University of Alberta Hospital, 20 beds in a cardiovascular surgical ICU.

\section{Patient population}

We reviewed all in-hospital standardized records of cardiac and respiratory arrests from Jan. 1, 2000, to Apr. 30, 2005. We selected records for those that occurred in the adult critical care units of the four study hospitals. We excluded arrests that involved pediatric patients or that occurred in the emergency department, operating theatre or noncritical care areas. We included only the first arrest for patients who had more than one. We excluded patients who did not need manual cardiopulmonary resuscitation (CPR), defibrillation, cardioversion, emergency pacing or emergency mechanical ventilation.

Ethics approval of the study was obtained from the Health Research Ethics Boards of the University of Alberta and Covenant Health.

\section{Data collection}

We obtained patient data from medical records, vital statistics, and the patient's family or family physician, including the patient's age, location of arrest, APACHE II (Acute Physiology and Chronic Health Evaluation) score and whether the patient survived. To determine the duration of CPR, we considered the start time to be the arrival of the code team leader. The code record was used to determine the timing for the return of spontaneous circulation.

\section{Statistical analysis}

We calculated crude survival proportions by dividing the number of patients who survived by the total number of patients in each specified strata. We analyzed univariable associations between survival outcome at prespecified points and type of ICU, type of arrest, time of arrest, duration of CPR, APACHE II score on admission, and patient age and sex. The Pearson $\chi^{2}$ test and two-sided Fisher exact test were used. ${ }^{5}$ Duration of CPR was transformed using its natural logarithm to comply with normality assumptions for all statistical comparisons. We compared mean logarithm of CPR durations using the Student $t$ test.

Factors associated with survival that achieved a level of significance of $p \leq 0.25$ on univariable analysis were fit into the logistic regression models that predicted immediate survival (within 24 hours after arrest). ${ }^{6}$ For survival from 24 hours after arrest to vital status on May 16, 2009, survival analysis was performed using a Kaplan-Meier estimator and Cox proportional hazards model.

We determined the final logistic regression models and Cox proportional hazard models by backward selection of aforementioned variables, maintaining factors that were significant at a $p$ value of 0.05 or less. $^{7}$ Final logistic regression analysis was performed for 507 patients with complete data (including 266 patients without APACHE II scores) who survived or died within 24 hours after arrest. We performed a sensitivity analysis of the logistic regression model for the 241 patients who had complete data and APACHE II scores.

Of the 258 patients who survived more than 24 hours after the arrest, 254 had complete data and were included in the Cox proportional hazard models. The first model included 129 patients who died within eight months after arrest and the second model included 125 who survived eight months or longer. Of these 254 patients, 119 had APACHE II scores; we performed sensitivity analyses for the 66 patients who died within eight months and the 53 who survived eight months or longer.

For sample size, we assumed an in-hospital mortality of $80 \%$, based on findings from our previous retrospective cohort study of mortality among non-ICU patients experiencing cardiac arrest (85\%). ${ }^{4}$ For $80 \%$ power, and a two-sided $\alpha$ of 5\% around a point estimate of $80 \%$ mortality, we calculated that 430 patients would be needed for the study sample. No provision was made for age, APACHE II score or duration of CPR on sample size.

\section{Results}

\section{Patient population}

A total 517 patients met the inclusion criteria: $204(39.5 \%)$ were in general ICUs, 278 (53.8\%) in coronary care units and $35(6.8 \%)$ in the cardiovascular surgical ICU. The mean age was 66.5 years, and $62.3 \%$ were male. APACHE II scores on admission to ICU were available for 251 patients; the mean score was 26.4 (Table 1).

\section{Characteristics of the arrests}

Arrests due to pulseless electrical activity or asystole were the most frequent (45.8\%) (Table 1). 
Arrests due to pulseless electrical activity, asystole and bradyarrhythmias occurred more frequently in the general ICUs than in the cardiovascular surgical ICU; arrests due to ventricular fibrillation or ventricular tachycardia were more common in the coronary care units than in the general ICUs $(p=0.005)$.

The mean duration of CPR was 19.9 minutes (median 14, range 0-189 minutes). The proportion of patients who did not have return of spontaneous circulation increased with increasing duration of CPR: $13.2 \%$ of patients after less than 5 minutes of CPR, as compared with $23.9 \%$ after 5-10 minutes; $39.4 \%$ after 10-19 minutes; $59.0 \%$ after $20-29$ minutes; $66.1 \%$ after $30-44$ minutes; $67.7 \%$ after $45-59$ minutes; and $54.2 \%$ after 60 minutes or more. There was no association between duration of CPR and the time of day in which the arrest occurred $(p=0.43)$.

\section{Survival outcomes}

Of the 517 patients, 307 (59.4\%) had return of spontaneous circulation following initial CPR, $156(30.2 \%)$ survived to discharge from ICU, 138 (26.7\%) survived to discharge from hospital, 126 (24.3\%) survived to one year, and 83 (15.9\%) survived to five years. At one-year follow-up, $10.6 \%$ of patients whose arrest was due to pulseless electrical activity or asystole were alive, as compared with $36.3 \%$ of those with other arrest rhythms. Significantly fewer patients died before discharge from the cardiovascular surgical ICU $(16 / 35[45.7 \%])$ than from either the coronary care units (190/278 [68.3\%]) or the general ICUs $(155 / 204,76.0 \%)(p=0.001)$. Similarly, significantly fewer patients who were admitted to the cardiovascular surgical ICU died before discharge from hospital (16/35 [45.7\%]) compared with those who were admitted to a coronary care unit $(198 / 278[71.2 \%])$ or a general ICU $(165 / 204$ [80.9\%]) $(p<0.001)$.

In the univariable analysis, we found no significant association between type of hospital (tertiary v. community) and survival after initial CPR ( $p=$ $0.68)$, survival to ICU discharge $(p=0.43)$ or survival to hospital discharge $(p=0.18)$. We found no significant association between the time of day of the arrest and survival after initial CPR ( $p=$ $0.23)$ or survival to hospital discharge $(p=0.42)$.

Longer duration of CPR was associated with an increased risk of death within 24 hours after arrest (odds ratio [OR] 2.70, 95\% confidence interval $[\mathrm{CI}] 2.02-3.30$, per additional logarithm of a minute of CPR). The mean duration of CPR for arrests due to pulseless electrical activity or asystole was 24.0 minutes (median 18.0, range 0 189), which was significantly longer than the mean duration of 16.5 minutes (median 10, range
Table 1: Characteristics and stage of survival of 517 adults who experienced a cardiac or respiratory arrest in an intensive care unit (ICU)

$\begin{array}{cc}\text { Characteristic } & \text { No. (\%) } \\ \text { of patients* }\end{array}$

\begin{tabular}{lr}
\hline Stage of survival & \\
\hline Survived resuscitation from arrest & $307(59.4)$ \\
\hline Survived to ICU discharge & $156(30.2)$ \\
\hline Survived to hospital discharge & $138(26.7)$ \\
\hline Survived to one year & $126(24.3)$ \\
\hline Survived to five years & $83(15.9)$
\end{tabular}

\begin{tabular}{|lc|}
\hline Age, yr & $66.5(14.9)$ \\
\hline Mean (SD) & $70.0(15-94)$ \\
\hline Median (range) & \\
\hline Sex & $322(62.3)$ \\
\hline Male & $195(37.7)$ \\
\hline Female & $n=251 \dagger$ \\
\hline APACHE II score & $26.4(11.5)$ \\
\hline Mean (SD) & $27(1-54)$ \\
\hline Median (range) & \\
\hline Type of ICU & $278(53.8)$ \\
\hline Coronary care unit & $204(39.5)$ \\
\hline General ICU & $35(6.8)$ \\
\hline Cardiovascular surgical ICU
\end{tabular}

\section{Type of arrest}

Asystole or pulseless electrical 237 (45.8) activity

Ventricular tachycardia or $\quad 174$ (33.7)
fibrillation

\begin{tabular}{|lc|}
\hline Bradycardia or atrioventricular block & $80(15.5)$ \\
\hline Supraventricular tachycardia & $15(2.9)$ \\
\hline Respiratory arrest & $11(2.1)$ \\
\hline Time of arrest & $n=514$ \\
\hline $0801-1600$ & $188(36.6)$ \\
\hline $1601-2400$ & $159(30.9)$ \\
\hline $0001-0800$ & $167(32.5)$ \\
\hline Duration of CPR, min & $76(14.7)$ \\
\hline$<5$ & $113(21.9)$ \\
\hline $5-9.9$ & $132(25.6)$ \\
\hline $10-19.9$ & $78(15.1)$ \\
\hline 20-29.9 & $62(12.0)$ \\
\hline $\begin{array}{l}\text { 30-44.9 } \\
\text { 45-59.9 }\end{array}$ & $31 \quad(6.0)$ \\
\hline$\geq 60$ & $24 \quad(4.7)$ \\
\hline $\begin{array}{l}\text { Mean (SD) } \\
\text { Median (range) }\end{array}$ & $19.9(19.5)$ \\
\hline $\begin{array}{l}\text { Note: APACHE = Acute Physiology and Chronic Health } \\
\text { Evaluation, CPR = cardiopulmonary resuscitation, SD = } \\
\text { *Undard deviation. } \\
\text { †APACHE II scores on admission to ICU were available for } \\
\text { 251 patients. }\end{array}$ \\
\hline
\end{tabular}


$0-100)$ for other types of arrest $(p<0.001)$. Among patients whose arrest was due to pulseless electrical activity or asystole, those who survived to hospital discharge had a significantly shorter mean duration of CPR (21.0 minutes; median 13.5 minutes) than did patients who died before hospital discharge (mean 24.4 minutes; median 19.0 minutes $)(p=0.03)$. No patient achieved return of spontaneous circulation if CPR exceeded 189 minutes; no patient survived to hospital discharge if CPR exceeded 80 minutes.

The strongest predictor of death within 24 hours after arrest, regardless of ICU type, was arrest due to pulseless electrical activity or asystole (OR 3.88, 95\% CI 2.68-5.63) compared with other rhythms (Table 2). Eighty-six per cent of patients with an APACHE II score of 25 or higher and $94.7 \%$ of those with a score of 40 or higher died on or before hospital discharge, irrespective of arrest type. Similarly, no patient survived to hospital discharge following an arrest due to pulseless electrical activity or asystole if their APACHE II score was 30 or higher (Figure 1, top panel). We found no significant association between duration of CPR and survival to hospital discharge among patients with pulseless electrical activity or asystole or among those who had other arrest rhythms ( $p=0.26$ ) (Figure 1, bottom panel).

As in the univariable logistic regression analysis, in the multivariable model, age, type of ICU and APACHE II score were not independent predictors of death within 24 hours after arrest. Male sex (adjusted OR 1.55, 95\% CI 1.01-2.36), arrest due to pulseless electrical activity or asystole (adjusted OR 3.37, 95\% CI 2.24-5.07) and longer duration of CPR (adjusted OR 2.59, 95\% CI 2.02-3.30, per additional logarithm of a minute of CPR) were associated with an increased risk of death within 24 hours (Table 2). When we limited the model to the 241 patients with an APACHE II score, we found little change in the magnitude of effect of the other covariates.

In the Kaplan-Meier analysis of survival outcomes after the first 24 hours following arrest until May 16, $2009(n=258)$, the mean survival period was 2.56 (standard deviation [SD] 2.00) months among the 78 patients with pulseless electrical activity or asystole. This period was significantly shorter than the mean survival period of 3.80 (SD 3.49) months among the 180 patients with other types of arrest (Wilcoxon $p<$ 0.001) (Figure 2). Mortality differed significantly between those whose arrest was due to pulseless electrical activity or asystole and those with other types of arrest $(\log$ rank $p<0.001$, Wilcoxon $p<0.001$ ).

The hazard functions crossed at between seven and eight months: patients whose arrest was due to pulseless electrical activity or asystole had a greater hazard of dying within eight months after arrest and a lower hazard of dying after eight months compared with patients who had other types of arrest. Consequently, we stratified the Cox proportional hazard analysis into two models reflecting these periods (Table 3). From the day after arrest until eight months, longer duration of CPR was the only independent predictor of death (adjusted hazard ratio [HR] 1.50, 95\% CI 1.18-1.91, per additional logarithm of a minute of CPR). From eight months until the end

Table 2: Odds ratios for risk of death within 24 hours after cardiac or respiratory arrest among 517 patients whose arrest occurred in an intensive care unit (ICU)

\begin{tabular}{|c|c|c|c|}
\hline \multirow[b]{2}{*}{ Variable } & \multirow[b]{2}{*}{$\begin{array}{l}\text { Crude OR }(95 \% \mathrm{Cl}) \\
\quad n=517\end{array}$} & \multicolumn{2}{|c|}{ Adjusted OR $(95 \% \mathrm{Cl})$ * } \\
\hline & & $\begin{array}{c}\text { Model } 1 \dagger \\
n=241\end{array}$ & $\begin{array}{l}\text { Model } 2 \ddagger \\
n=507\end{array}$ \\
\hline Age (per year increase) & $1.00(0.99-1.01)$ & & \\
\hline Male (v. female) sex & $1.24(0.86-1.78)$ & $1.89(1.02-3.50)$ & $1.55(1.01-2.36)$ \\
\hline $\begin{array}{l}\text { Arrest due to pulseless electrical } \\
\text { activity or asystole (v. other types of } \\
\text { arrest) }\end{array}$ & $3.88(2.68-5.63)$ & $3.90(2.14-7.10)$ & $3.37(2.24-5.07)$ \\
\hline $\begin{array}{l}\text { Duration of CPR (per additional } \\
\text { logarithm of minute of CPR) }\end{array}$ & $2.70(2.02-3.30)$ & $2.47(1.71-3.56)$ & $2.59(2.02-3.30)$ \\
\hline $\begin{array}{l}\text { APACHE II score (per 1-point } \\
\text { increase) } n=251\end{array}$ & $1.02(1.00-1.05)$ & $1.01(0.99-1.04)$ & \\
\hline $\begin{array}{l}\text { Cardiovascular surgical ICU (v. other } \\
\text { types of ICU) }\end{array}$ & $0.56(0.26-1.20)$ & & \\
\hline \multicolumn{4}{|c|}{$\begin{array}{l}\text { Note: APACHE = Acute Physiology and Chronic Health Evaluation, } \mathrm{Cl}=\text { confidence interval, CPR = cardiopulmonary resuscitation, } \\
\text { OR = odds ratio. } \\
\text { *Adjusted for age, sex, type of arrest, duration of CPR (logarithm of minutes), APACHE II score and type of ICU. } \\
\text { tModel } 1 \text { was restricted to the } 241 \text { patients who had complete data and APACHE II scores. } \\
\text { †Model } 2 \text { included all } 507 \text { patients who had complete data, including } 266 \text { patients without APACHE II scores. }\end{array}$} \\
\hline
\end{tabular}


of follow-up, increasing age (adjusted HR 1.06, 95\% CI 1.03-1.09) and longer duration of CPR (adjusted HR 1.38, 95\% CI 1.03-1.83) were independent predictors of death.

Sensitivity analysis limited to the patients with APACHE II scores who survived up to eight months $(n=66)$ and eight months or longer $(n=$ 53) did not influence the direction of effect of the duration of CPR. However, the variance of the effect of this variable did increase to the level that this factor was no longer significant in the restricted models containing fewer patients (Table 3 ).

\section{Interpretation}

Patient survival following cardiac or respiratory arrest in ICUs in our study was similar to patient survival reported in other studies of arrest in critical care units from the last two decades. ${ }^{8-13}$ In our study, about one in four patients $(24.3 \%)$ survived to one year, and about one in six (15.9\%) to five years. Survival was higher among our patients than among patients in previous studies whose arrest occurred in non-ICU hospital settings. ${ }^{4,1-20}$ About $60 \%$ of the patients in our study were initially resuscitated, and just over one-quarter survived to hospital discharge. In comparison, our previous study of survival outcomes following arrest in non-ICU hospital wards showed that about one-third regained a pulse, and $13 \%$ survived to hospital discharge. ${ }^{4}$ This difference suggests that cardiac or respiratory arrests in critical care units are distinct from those in non-ICU hospital wards. However, our ICU survival data are similar to those previously reported for witnessed arrests in non-ICU hospital wards. ${ }^{4}$ Collectively, the results of our two studies highlight the primacy of whether an arrest is witnessed over where the arrest occurs in hospital.

On average, survival to discharge from ICU for all patients has been reported to exceed $80 \%{ }^{21,22}$ In our study, only about $30 \%$ of the patients survived to ICU discharge after their arrest. Furthermore, at one-year follow-up, only $11 \%$ of patients whose arrest was due to pulseless electrical activity or asystole and $36 \%$ of those with other arrest rhythms were alive. The APACHE II score, a validated measure of the severity of acute illness in ICUs (but not coronary care units) ${ }_{,}^{23}$ was not an independent predictor of immediate or long-term death over its entire range. However, no patient survived to hospital discharge following an arrest due to pulseless electrical activity or asystole if their APACHE II score was 30 or higher. The independent predictors of death within 24 hours after arrest were male sex, arrest due to pulseless electrical activity or asystole, and longer duration of CPR. Predictors of longer term survival (eight

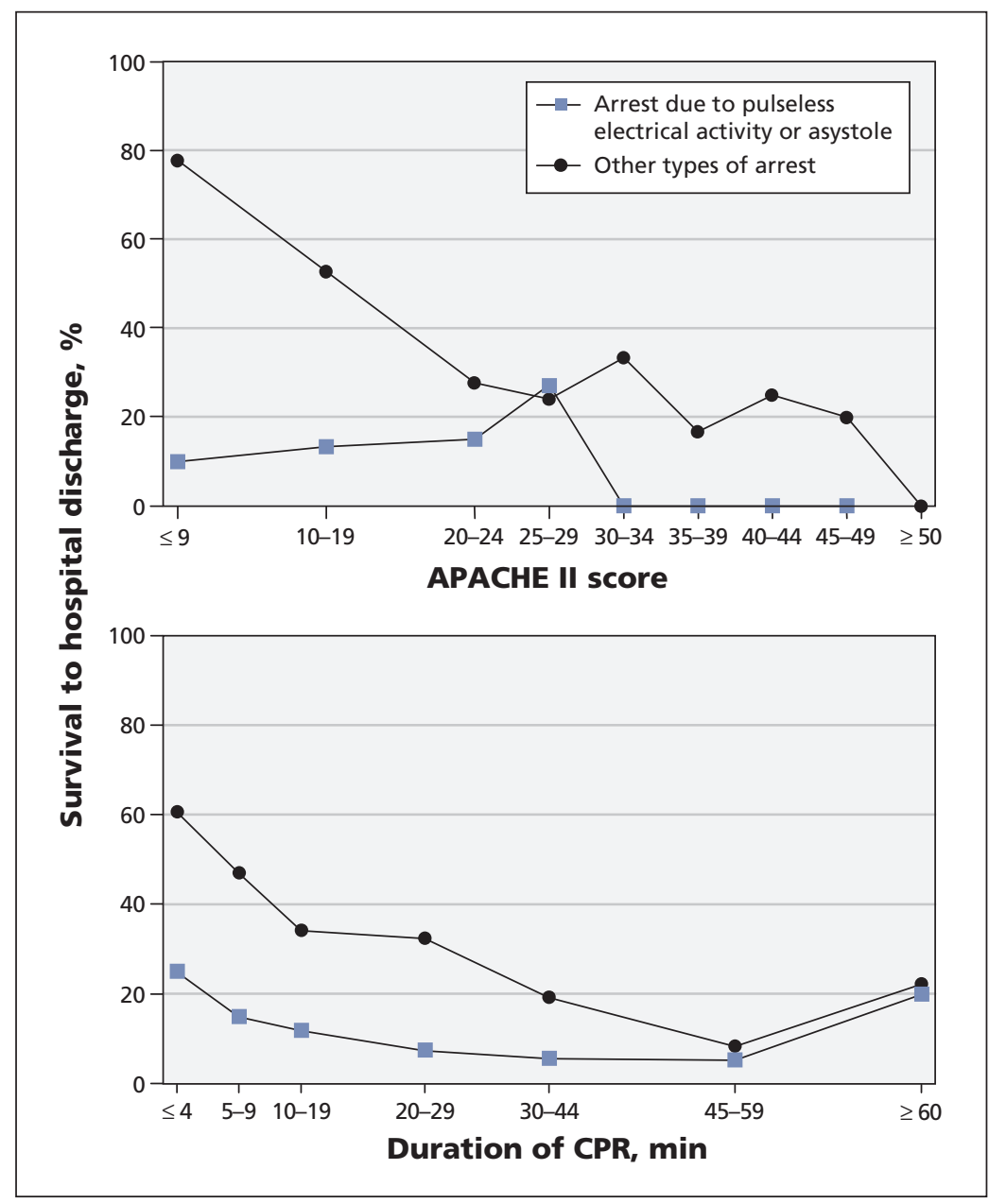

Figure 1: Top panel: Association between severity of illness (as measured by APACHE II score) and survival to hospital discharge among 251 patients with available APACHE II scores who had cardiac or respiratory arrest in an intensive care unit, by type of arrest. Bottom panel: Association between duration of cardiopulmonary resuscitation (CPR) and survival to hospital discharge among $\mathbf{5 1 6}$ patients with available data on duration of CPR who had cardiac or respiratory arrest in an ICU, by type of arrest.

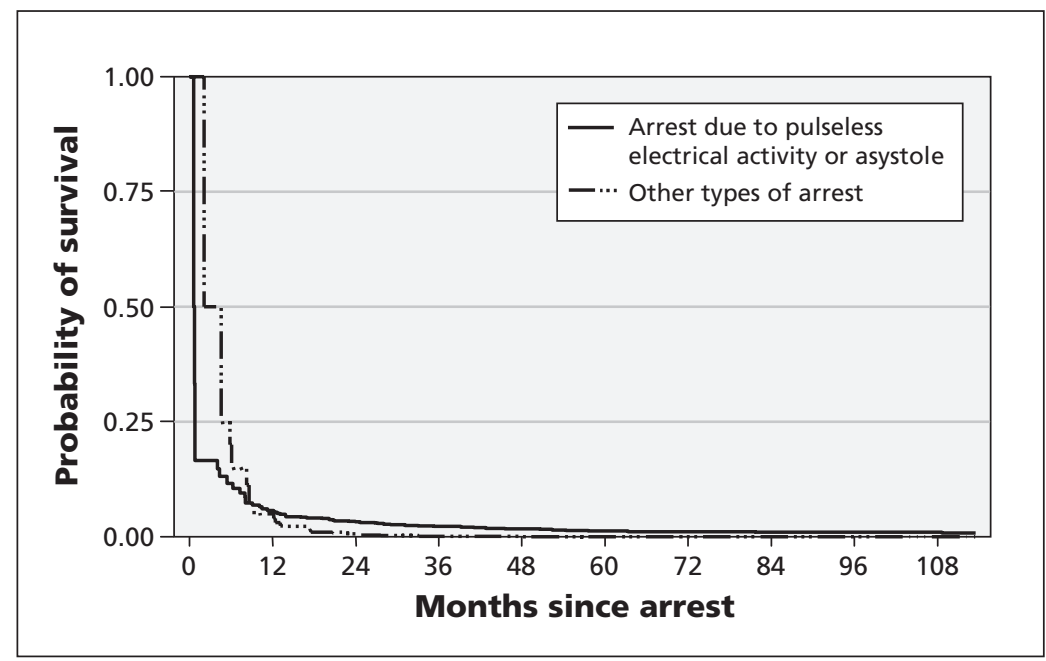

Figure 2: Kaplan-Meier curves for survival among 258 patients who were alive 24 hours after cardiac or respiratory arrest in an intensive care unit, by type of arrest. 
months or more) were increasing age and longer duration of CPR.

Studies of cardiac arrests occurring out of hospital have shown an increased incidence of arrests in early morning. This was attributed to the cortisol- and catecholamine-surge upon awakening. ${ }^{24-26}$ However, it was unclear whether this pattern would apply to critically ill in-patients, where circadian influence is lessened. ${ }^{27,28}$ Results from our previous study of arrests occurring in non-ICU hospital settings suggested decreased survival with early morning cardiac arrest. ${ }^{4}$ In the current study, we found no early morning peak in total arrests, and no excess of early morning arrests due to pulseless electrical activity or asystole. This may be due in part to higher 24-hour nurse-topatient ratios in critical care units. It may also be associated with the blunted endocrine response of prolonged critical illness..$^{27,28}$

One of the highest survival rates yet reported following cardiac arrest (53\%) was not in a hospital or an ICU setting; it was in a casino. ${ }^{29}$ Valenzuela and colleagues attributed this benefit to close observation, rapid response and a high percentage of arrests due to ventricular fibrillation. Similarily, a study involving laypeople using automated external defibrillators at an airport reported extremely high survival rates. ${ }^{30}$ Benefits were not attributed to specialized personnel or advanced equipment (beyond defibrillators). However, our ICU study results are still consistent with these findings, because they sug- gest the importance of rapid response and the influence of the type of arrest.

Our overall survival to hospital discharge of $26.9 \%$ was better than the $15.9 \%$ noted by Tian and coauthors, who reviewed the outcomes of 49656 adults with a first arrest in the ICU over a similar period using the US National Registry of Cardiopulmonary Resuscitation. ${ }^{31}$ This difference may have occurred because we had more patients with ventricular tachycardia and ventricular fibrillation and included patients admitted to coronary care units. We did not find an increased risk of death on evenings and weekends, as was found by Tian and coauthors. ICUs in which one-to-one or two-to-one nurse-to-patient ratios, supported by fully trained intensivists within a Canadian health care system, may have accounted for the lack of an association between mortality and the time of arrest. Moreover, although Tian and coauthors reported an increased mortality among patients taking pressor medications before their arrest, they did not measure illness severity, duration of CPR or survival outcomes after hospital discharge.

\section{Limitations}

Given the retrospective nature of our study, several limitations may introduce bias and limit generalizability. These include possible inaccuracies in charting, and possible failure to produce a record of cardiac or respiratory arrest for all appropriate patients. Ultimately our study was slightly underpowered, given an in-hospital mor-

Table 3: Factors associated with decreased survival among 254 patients with complete data who survived at least $\mathbf{2 4}$ hours after cardiac or respiratory arrest in an intensive care unit (ICU), by time since arrest*

\begin{tabular}{|c|c|c|c|c|}
\hline \multirow[b]{2}{*}{ Variable } & \multicolumn{2}{|c|}{$\begin{array}{l}\text { Survival }<8 \text { mo } \\
\quad n=129\end{array}$} & \multicolumn{2}{|c|}{$\begin{array}{l}\text { Survival } \geq 8 \mathrm{mo} \\
\quad n=125\end{array}$} \\
\hline & $\begin{array}{l}\text { Crude HR } \\
(95 \% \mathrm{Cl})\end{array}$ & $\begin{array}{l}\text { Adjusted HR } \\
(95 \% \mathrm{Cl}) \dagger\end{array}$ & $\begin{array}{l}\text { Crude HR } \\
(95 \% \mathrm{Cl})\end{array}$ & $\begin{array}{l}\text { Adjusted HR } \\
(95 \% \mathrm{Cl}) \dagger\end{array}$ \\
\hline Age (per year increase) & $0.98(0.97-1.00)$ & & $1.06(1.03-1.08)$ & $1.06(1.03-1.09)$ \\
\hline Male (v. female) sex & $1.33(0.81-2.18)$ & & $1.11(0.61-2.00)$ & \\
\hline $\begin{array}{l}\text { Arrest due to pulseless electrical } \\
\text { activity or asystole (v. other } \\
\text { types of arrest) }\end{array}$ & $1.19(0.70-2.02)$ & & $0.53(0.22-1.24)$ & \\
\hline $\begin{array}{l}\text { Duration of CPR (per } \\
\text { additional logarithm of } \\
\text { minute of CPR }\end{array}$ & $1.50(1.18-1.91)$ & $1.50(1.18-1.91)$ & $1.35(1.02-1.78)$ & $1.38(1.03-1.83)$ \\
\hline $\begin{array}{l}\text { APACHE II score (per 1-point } \\
\text { increase) }\end{array}$ & $1.02(0.98-1.08)$ & & $0.99(0.95-1.04)$ & \\
\hline $\begin{array}{l}\text { Cardiovascular surgical ICU } \\
\text { (v. other types of ICU) }\end{array}$ & $0.83(0.29-2.35)$ & & $0.56(0.20-1.57)$ & \\
\hline \multicolumn{5}{|c|}{$\begin{array}{l}\text { Note: APACHE = Acute Physiology and Chronic Health Evaluation, } \mathrm{Cl}=\text { confidence interval, CPR = cardiopulmonary resuscitation, } \\
\mathrm{HR}=\text { hazard ratio. } \\
\text { *The first model violated the proportional hazards assumption, because the hazard ratio associated with cardiac arrest due to } \\
\text { pulseless electrical activity or asystole was higher than that associated with other types of arrest in the first } 8 \text { months after the } \\
\text { arrest and was lower thereafter. } \\
\text { †Adjusted for age, sex, type of arrest, duration of CPR (logarithm of minutes), APACHE II score and type of ICU. }\end{array}$} \\
\hline
\end{tabular}


tality of $75 \%$, which meant we would have required a sample of 563 patients. We were limited to the comorbidity data derived as part of the APACHE II score. In addition, we included arrests only up until 2005, because we wanted to describe survival over five years, a longer period than is typical of most studies. Regardless, the choice of study period excludes any putative benefit from recent clinical advances ${ }^{32-34}$ or updated guidelines on advanced cardiac life support. ${ }^{35}$

\section{Conclusion}

Our study showed no major improvement in survival following cardiac arrest with pulseless electrical activity or asystole as the presenting rhythm in the ICU despite many advances in critical care over the previous two decades. Although overall survival among ICU patients may have greatly improved, survival among those experiencing cardiac arrest in the ICU, particularly arrest due to pulseless electrical activity or asystole, remained comparatively poor. The independent predictors of death within 24 hours after arrest in an ICU were sex, the presenting rhythm and the duration of CPR. Predictors of later death (eight months or more after arrest) were age and duration of CPR. A key strategy to prevent or mitigate arrests needs to include earlier identification and response.

\section{References}

1. Zheng ZJ, Croft JB, Giles WH, et al. Sudden cardiac death in the United States, 1989 to 1998. Circulation 2001;104:2158-63.

2. Kouwenhoven WB, Jude JR, Knickerbocker GG. Closed-chest cardiac massage. JAMA 1960;173:1064-7.

3. Ewanchuk ME, Brindley PG. Perioperative do-not-resuscitate orders - doing "nothing" when "something" can be done. Crit Care 2006;10:219-23.

4. Brindley PG, Markland DM, Mayers I, et al. Predictors of survival following in-hospital adult cardiopulmonary resuscitation. CMAJ 2002;167:343-8.

5. Rosner B. Fundamentals of biostatistics. Belmont (CA): Duxbury Press; 1995.

6. Hosmer DW, Lemeshow S. Applied logistic regression. New York (NY): John Wiley and Sons; 1989.

7. Kalbfleisch JD, Prentice RL. The statistical analysis of failure time date. Hoboken (NJ): John Wiley and Sons; 2002.

8. Nadkarni VM, Larkin GL, Peberdy MA, et al.; National Registry of Cardiopulmonary Resuscitation Investigators. First documented rhythm and clinical outcome from in-hospital cardiac arrest among children and adults. JAMA 2006;295:50-7.

9. Dhar A, Ostryzniuk K, Roberts DE, et al. Intensive care unit admission following successful cardiopulmonary resuscitation: resource utilization, functional status and long-term survival. Resuscitation 1996;31:235-42.

10. Chang S-H, Huang C-H, Shih CL, et al. Who survives cardiac arrest in the intensive care units? J Crit Care 2009;24:408-14.

11. Enohumah KO, Moerer O, Kirmse C, et al. Outcome of cardiopulmonary resuscitation in intensive care units in a university hospital. Resuscitation 2006;71:161-70.

12. Myrianthefs P, Kalafati M, Lemonidou C, et al. Efficacy of CPR in a general, adult ICU. Resuscitation 2003;57:43-8.

13. Peterson MW, Geist LJ, Schwartz DA. Outcome after cardiopulmonary resuscitation in a medical intensive care unit. Ches 1991;100:168-74.

14. Robinson GR, Hess D. Postdischarge survival and functional status following in-hospital cardiopulmonary resuscitation. Chest 1994;105:991-6.

15. Rosenberg M, Wang C, Hoffman-Wilde S. Results of cardiopulmonary resuscitation. Arch Intern Med 1993;153:1370-5.
16. Berger R, Kelley M. Survival after in-hospital cardiopulmonary arrest of noncritically ill patients - a prospective study. Chest 1994;106:872-9.

17. Doig CJ, Boiteau PJ, Sandham JD. A 2-year prospective cohort study of cardiac resuscitation in a major Canadian hospital. Clin Invest Med 2000;23:132-43.

18. Tresch DD, Thakur RK. Cardiopulmonary resuscitation in the elderly - beneficial or an exercise in futility. Emerg Med Clin North Am 1998;3:649-63.

19. Ballew KA, Philbrick JT, Caven DE, et al. Predictors of survival following in-hospital cardiopulmonary resuscitation. Arch Intern Med 1994;154:2426-32.

20. Roberts D, Landolfo K, Light RB. Early predictors of mortality for hospitalized patients suffering cardiopulmonary arrest. Chest 1990;97:413-9.

21. Knaus WA, Harrell FE, Lynn J, et al.; Support investigators. The SUPPORT prognostic model. Objective estimates of survival for seriously-ill hospitalized adults. Study to understand prognoses and preferences for outcomes and risks of treatments. Ann Intern Med 1995;122:191-203.

22. Sinuff T, Adhikari NK, Cook DJ, et al. Mortality predictions in the intensive care unit: comparing physicians with scoring systems. Crit Care Med 2006;34:878-85.

23. Knaus WA, Draper EA, Wagner DP, et al. APACHE II: a severity of disease classification system. Crit Care Med 1985;13:818-29.

24. Willich SN, Levy D, Rocco MB, et al. Circadian variation in the incidence of sudden cardiac death in the Framingham Heart Study population. Am J Cardiol 1987;60:801-6.

25. Muller JE, Ludner PL, Willich SN, et al. Circadian variation in the frequency of sudden cardiac death. Circulation 1987;75:131-8.

26. Muller JE, Stone PH, Turi ZG, et al.; MILIS Study Group. Circadian variation in the frequency of onset of acute myocardial infarction. N Engl J Med 1985;313:1315-22.

27. Van den Berghe G, de Zegher F, Veldhuis JD, et al. The somatotropic axis in critical illness: effect of continuous growth hormone $(\mathrm{GH})$-releasing hormone and GH-releasing peptide-2 infusion. J Clin Endocrinol Metab 1997;82:590-9.

28. Van den Berghe G, Wouters P, Bowers CY, et al. Growth hormone-releasing peptide-2 infusion synchronizes growth hormone, thyrotrophin and prolactin release in prolonged critical illness. Eur J Endocrinol 1999;140:17-22.

29. Valenzuela TD, Roe DJ, Nichol G, et al. Outcomes of rapid defibrillation by security officers after cardiac arrest in casinos. N Engl J Med 2000;343:1206-9.

30. Caffrey SL, Willoughby PJ, Pepe PE, et al. Public use of automated external defibrillators. N Engl J Med 2002;347:1242-7.

31. Tian J, Kaufman DA, Zarich S, et al. Outcomes of critically ill patients who received cardiopulmonary resuscitation. Am J Respir Crit Care Med 2010;182:501-6.

32. The Acute Respiratory Distress Syndrome Network. Ventilation with lower tidal volumes as compared with traditional tidal volumes for acute lung injury and the acute respiratory distress syndrome. N Engl J Med 2000;342:1301-8.

33. Rivers E, Nguyen B, Havstad S, et al. Early goal-directed therapy in the treatment of severe sepsis and septic shock $N$ Engl $J$ Med 2001;345:1368-77.

34. Hillman K, Chen J, Cretikos M, et al.; MERIT study investigators. Introduction of the medical emergency team (MET) system: a cluster-randomised controlled trial. Lancet 2005;365:2091-7.

35. Committee ECC; Subcommittees and Task Forces of the American Heart Association. 2005 American Heart Association Guidelines for Cardiopulmonary Resuscitation and Emergency Cardiovascular Care. Circulation 2005;112:IV1-203.

Affiliations: From the Divisions of Critical Care Medicine (Kutsogiannis, Bagshaw, Brindley) and Cardiac Surgery (Laing), University of Alberta, Edmonton, Alta.

Contributors: All of the authors contributed to the study design and the collection of data. Demetrios Kutsogiannis and Sean Bagshaw provided statistical analysis. All of the authors contributed to the drafting and revision of the manuscript and approved the final version submitted for publication.

Funding: Funding for the study was obtained from the research budget of the Critical Care Division, University of Alberta; the Royal Alexandra Hospital Foundation provided research nursing support for data abstraction and editing.

Acknowledgement: The authors acknowledge the work of Mrs. Patrica Thompson, who assisted with data abstraction and editing. 